\title{
Contribution of Cytology for the Diagnosis of Gallbladder Carcinoma to Avoid Misdiagnosis in This Commonly Resected Organ
}

\author{
Salah Berkane ${ }^{1,2 *}$, Salim Belkherchi',2, Ali Bendjaballah ${ }^{3,4}$ \\ ${ }^{1}$ Department of General and Oncologic Surgery, Bejaia Teaching Hospital, Bejaia, Algeria \\ ${ }^{2}$ Faculty of Medicine, University of Bejaia, Bejaia, Algeria \\ ${ }^{3}$ Department of General Surgery, Ain Taya Hospital, Algiers, Algeria \\ ${ }^{4}$ Faculty of Medicine, University of Algiers, Algiers, Algeria \\ Email: *salahberkane07@yahoo.fr
}

How to cite this paper: Berkane, S., Belkherchi, S. and Bendjaballah, A. (2020) Contribution of Cytology for the Diagnosis of Gallbladder Carcinoma to Avoid Misdiagnosis in This Commonly Resected Organ. Surgical Science, 11, 74-81.

https://doi.org/10.4236/ss.2020.114010

Received: February 27, 2020

Accepted: April 21, 2020

Published: April 24, 2020

Copyright $\odot 2020$ by author(s) and Scientific Research Publishing Inc. This work is licensed under the Creative Commons Attribution-NonCommercial International License (CC BY-NC 4.0). http://creativecommons.org/licenses/by-nc/4.0/

\begin{abstract}
The cytological study of gallbladder bile is a diagnostic tool used very often in the treatment of gallbladder cancer. The diagnosis of gall bladder cancer is done by morphological examinations such as ultrasound, computed tomography in $80 \%$ of cases, but in some difficult cases, benign lesions associated with malignant lesions, such as pseudo-tumoral cholecystitis, adenomyosis or adenoma and cancers requiring medical treatment by chemotherapy or radiotherapy, is without the possibility of surgical treatment. Cytology can help resolve a number of difficult situations, such as the presence of an intra-gallbladder lesion in the form of a polyp or nodule. Some studies have reported very interesting results from gallbladder cytology to cancer diagnosis with results up to $85 \%$ sensitivity. The purpose of this study is to analyze the contribution of the cytological study of gallbladder bile to the positive diagnosis of gallbladder cancer.
\end{abstract}

\section{Keywords}

Cytological Study, Gallbladder, Diagnosis of Gallbladder Cancer, Surgical Treatment, Diagnostic Tool

\section{Introduction}

The diagnosis of gallbladder cancer is done by different morphological examinations such as ultrasonography, computed tomography, etc. [1]. On the other hand for certain difficult situations as benign lesions taken to malignant lesions such as tumor-cholecystitis, adenomyosis or adenoma and cancers that require medical treatment by chemotherapy or radiotherapy are beyond the possibilities of 
surgical treatment [2]. In these cases it is important to have evidence of malignant or benign lesions in order to decide how to manage each situation. Some conditions are simple to resolve such a strictly localized lesion to the gallbladder as a polyp, a first cholecystectomy as frozen section may be considered, but the majority of lesions pose a difficult problem when the diagnosis remains imprecise [3]. How to make the diagnosis certain: either by the use of a cholecystectomy, a biopsy or cytology of the gallbladder bile? Each method has these advantages and disadvantages. Some studies have reported very interesting results from the cytological study of gallbladder bile to cancer diagnosis with results up to $85 \%$ sensitivity [4].

\section{Material and Method}

This is a prospective study involving 68 patients undergoing a benign or malignant gallbladder. The patients included are those operated for cancer and a benign lesion of the gallbladder. Some healthy-looking gallbladders were also included in this study because they were resected for another hepatic biliary disease (e.g. hydatid cyst of the liver).

The sampling technique is made as follows:

1) Taking $10 \mathrm{cc}$ bile from the gallbladder intraoperatively by puncturing the gallbladder;

2) Adding $10 \mathrm{cc}$ alcohol or formalin diluted to $10 \%$ in $10 \mathrm{cc}$ of bile.

The preparation technique for reading kit Ral:

1) Fixing alcohol;

2) Eosin;

3) Hemalun;

4) Rinse with water.

The technique of cell block:

\section{Hematin-Eosin}

The distribution of patients into 2 groups:

The fixed samples are studied by the histologist several days later and not immediately. We started this method for some cases in this way after having a good relationship in these cases. This prospective study was started after having demonstrated that when the samples are well fixed, the cytology will be better. Our patients were divided in two groups:

$\rightarrow$ Group A: patients with gallbladder cancer;

$\rightarrow$ Group B: patients with benign pathologies of the gallbladder. It is the control group.

We considered the sensitivity, the specificity, the positive predictive value and the negative predictive value. The basic review is based on the histological study of gall bladder examination performed on standard samples.

\section{Results}

We collected 68 patients divided in two groups 38 cancers of gallbladder and 30 benign lesions of gallbladder. There are 51 women (75\%) and 17 males (25\%). 
The mean age is 54.9 years ( 22 - 83 years). All patients in the first group (A) had adenocarcinoma. In the second group (B), the lesions are distributed as follows: 1 adenoma, 2 adenomyosis, 2 healthy gallbladder wall and 25 with inflammatory lesions (Table 1). Overall, the material described in cytology was clean, rich, or hemorrhagic. The cellular elements are epithelial cell with atypical nuclei in case of malignant cytology (Figure 1) and epithelial with inflammatory cells in case of benign lesions (Figure 2). The cellular organization was either isolated, in clusters or nests. In Group A, the macroscopic type of tumors was represented by 17 diffuse tumors, 16 polyp lesion, 3 thickening wall and 2 nodular lesions. Malignant cytology was found in 31 cases in the group of 38 patients (81.5\%). Seven patients who had initially adenocarcinoma the cytology study was found to be benign in the final cytological result. The false negative rate is $18.5 \%$. We did not find any positive false (Table 2). Conferring to the macroscopic type of tumor of the gallbladder, the sensitivity was $80.3 \%$ for the polyp lesion, $82.4 \%$ for the diffuse lesion, $75 \%$ for thickening wall lesion and $50 \%$ for nodular lesion (Table 3). The sensitivity, the specificity, the positive predictive value and the negative predictive value are respectively $81.7 \%, 100 \%, 100 \%$ and $81 \%$ (Table 4 ).

Table 1. Macroscopic and microscopic aspect of gallbladder lesions.

\begin{tabular}{|c|c|c|c|c|}
\hline & \multicolumn{2}{|c|}{ Group A: } & \multicolumn{2}{|l|}{ Group B: } \\
\hline & \multicolumn{2}{|l|}{38} & \multicolumn{2}{|l|}{30} \\
\hline Females & \multicolumn{2}{|l|}{30} & \multicolumn{2}{|l|}{25} \\
\hline Males & \multicolumn{2}{|l|}{10} & \multicolumn{2}{|l|}{05} \\
\hline Age & \multicolumn{2}{|c|}{ 57years (45 - 75 years) } & \multicolumn{2}{|l|}{50 (35 - 74 years $)$} \\
\hline $\begin{array}{c}\text { Microscopic } \\
\text { aspect }\end{array}$ & \multicolumn{2}{|c|}{ Adenocarcinoma } & $\begin{array}{c}\text { Adenoma } \\
\text { Adenomyosis } \\
\text { Healthy wall } \\
\text { Acute and chronic cholecystitis }\end{array}$ & \\
\hline \multirow{5}{*}{$\begin{array}{c}\text { Macroscopic } \\
\text { aspect }\end{array}$} & Diffuse tumor & 17 & Adenoma & 01 \\
\hline & Polyp & 16 & Adenomyosis & 02 \\
\hline & Nodule & 2 & Healthy wall & 02 \\
\hline & Thickening wall & 3 & Acute or chronic cholecystitis & 25 \\
\hline & & 38 & & 30 \\
\hline
\end{tabular}

Table 2. Sensitivity of cytology. No false positive for benign lesions but $18.5 \%$ false negative for malignant lesion.

\begin{tabular}{ccc}
\hline Histopathology & Malignant cytology & Benign cytology \\
\hline Adenocarcinoma & $31 / 38(81.5 \%)$ & $07 / 38(18.5 \%)$ \\
Adenoma & $00 / 01(00 \%)$ & $01 / 01(100 \%)$ \\
Adenomyosis & $00 / 00(00 \%)$ & $02 / 02(100 \%)$ \\
Inflammatory lesions & $00 / 23(00 \%)$ & $23 / 23(100 \%)$ \\
Healthy wall & $00 / 02(00 \%)$ & $02 / 02(100 \%)$ \\
\hline
\end{tabular}




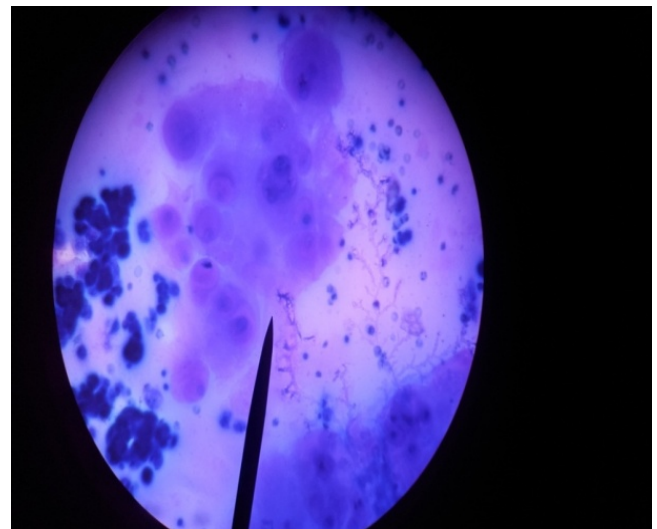

Figure 1. Malignant cytology: cluster of cohesive cells with high N/C ratio, atypical nuclei and nucleolus. MGG $\times 40$.

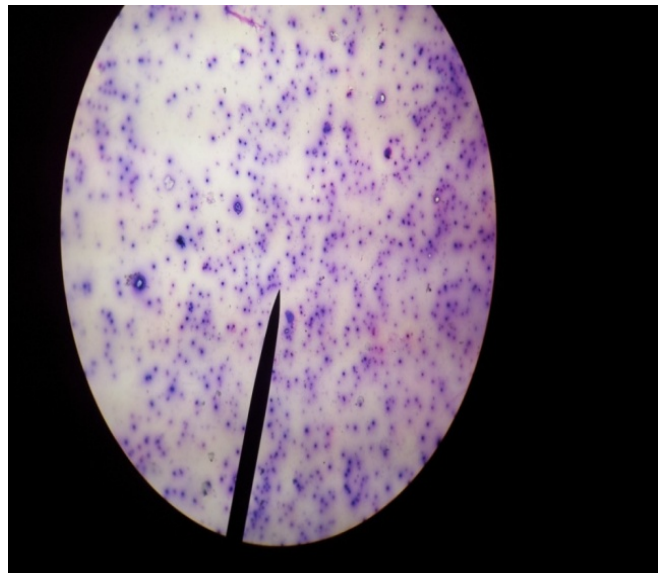

Figure 2. Benign cytology: moderate circularity, regular epithelial cells on a serous background. MGG $\times 40$.

Table 3. Sensitivity of biliary cytology according to the macroscopic type (Malignant lesion).

\begin{tabular}{ccccc}
\hline Macroscopic aspect & Number & Malignant cytology & Benign cytology & Percentage \% \\
\hline Diffuse tumor & 17 & 14 & 3 & $82.4 \%$ \\
Polyp & 16 & 14 & 2 & $87.5 \%$ \\
Nodule & 2 & 1 & 1 & $50 \%$ \\
Thickening wall & 3 & 2 & 1 & $67.7 \%$ \\
Total & 38 & 31 & 7 & $81.5 \%$ \\
\hline
\end{tabular}

Table 4. Diagnostic values of cytology of bile from the gallbladder.

\begin{tabular}{cc}
\hline Variable & Percentage \\
\hline Sensitivity (Se) & $81.6 \%$ \\
Specificity (Sp) & $100 \%$ \\
Positive predictive value (PPV) & $100 \%$ \\
Negative predictive value (NPV) & $81 \%$
\end{tabular}




\section{Discussion}

The understanding of the cytological study of the gallbladder is a useful support for the diagnosis of cancer in variable situations. Currently this histological study has become the "gold standard" in this field. Some publications have reported some interesting results.

Some publications have reported interesting results [4]. Several situations can be helped by cytology such as the presence of an isolated lesion in the mucosa of gallbladder as a polyp or nodule [5], acute cholecystitis can simulating cancer [6] which is a very challenging condition. In case of acute or chronic cholecystitis that mimics cancer or a combination of both, it is very important to establish the diagnosis of cancer for appropriate treatment [7]. The time of performing this cytological examination is very important to consider, it can be performed preoperatively, either by fine needle aspiration cytology guided by ultrasound or by CT [8], or during endoscopic examination [9]. The sensitivity of cytology is $67 \%$ to $85 \%$ in the literature [10] [11]. Several techniques have been described. C. Vallilenga et al. [10] used a cytology study by apposition on the mucous of gallbladder for subclinical tumors. The sensitivity, specificity, positive predictive value and negative predictive value were $80 \%, 100 \%, 100 \%$ and $97.7 \%$. But when macroscopically obvious forms are included this statistics (numbers) pass to $89.6 \% 100 \%$, $100 \%$ and $98 \%$ [5].

For this author, cytological study is a valuable aid in the diagnosis of gallbladder cancer at an early or useful stage. In the same state of mind, V.K. Arora et al. [11] studied the gallbladder's bile of 40 patients in order to diagnose early forms of cancer. Two in situ cancers and invasive cancer have been diagnosed. The authors concluded that cytology is feasible for detecting cancer either in situ or invasive type. Alonzo Ruiz et al. [4] studied the bile of 374 cholecystectomized patients for gallbladder stones. The examination was considered correct in 205 cases. Of the 13 gallbladder cancers, no false positives were observed while 2 false negatives were detected by histological examination. The authors concluded after this examination of the existence of a good correlation with cytology and cancers in situ or invasive, whereas this one (correlation) decreased for the other tumoral lesions. Ishikawa et al. studied two different methods of bile gallbladder. Sampling was done directly by aspiration and the other after dilution of the bile. They concluded that there is a better diagnostic performance observed with the dilution method. Akosa et al. performed a study on gallbladder bile according to the sampling technique used: either by fine needle aspiration, or by brushing during ERCP or after intraoperative puncture [6]. They reported a total sensitivity of $50 \%$ of the cases. Most authors use cytology immediately after sampling because of the risk of cell lysis. In our study, it was found impossible to carry out an immediate cytological study of the samples and the samples were fixed either with formaldehyde or with alcohol. The cytological study is carried out several days after fixation of the samples. This is to our knowledge the first series of cytological studies reported on bile fixed and studied several days after its sample.

What is the interest of the practice of cytology? It seems that there are two 
situations to consider:

1) The differential diagnosis of invasive cancer of the gall bladder and acute cholecystitis with advanced lesion where the treatment is generally aggressive for cancer. Here, it is important to have an accurate diagnosis to adapt the surgical treatment [12].

2) The differential diagnosis between early gallbladder cancer (polyp or nodule or suspect thickening) and other benign (benign polyp or thickened wall) should be well clarified [11].

3) The systematic diagnosis of cancer on an apparently healthy wall but this situation concerns a particular slice of gallbladder cancer [13].

For the first two situations, cytology can be performed using an ultrasound or CT scan to collect gallbladder bile. During endoscopic cholangiography bile can be collect for cytological study. For the 3 situations, cytology can be performed intraoperatively by making the collection of the gallbladder bile by puncture of the gallbladder or after cholecystectomy. A very particular situation is where the gallbladder is in the form of a patent tumor or infiltration of sub-adjacent organs. This is really where puncture cytology allows a diagnosis without having to perform a cholecystectomy that will have very negative consequences on the patient's condition (spread of the tumor). In the case of limited lesions (polyps or other focal lesions), a cholecystectomy with histological study of the gallbladder competes with a cytological study of the bile alone.

The preoperative cytological study must be performed to determine the timing of the intervention. Its objective is to carry out a cytological study in frozen section. Morality The role of the cytological study is to avoid spillage of the tumor when the biopsy of the tumor is performed. Finally, to be complete, cytology is also a useful review of cases of untreated gallbladder cancer. This cytology will allow to start a suitable chemotherapy. It will be the same in the absence of bile in the gallbladder (sclero-atrophic gallbladder). In this case, the histological examination of the specimen will remain the only means of diagnosis using modern examinations more efficient [14].

\section{Conclusion}

Cytology of gallbladder bile is a diagnostic tool widely used in the treatment of gallbladder cancer. The sensitivity rate of about $85 \%$ with the specificity rate of $100 \%$ is a strong argument for the generalization of this attitude. However, it remain several situations of deficiency and a diagnosis uncertainty which still constitute a poorly adapted and therefore a poorly adapted treatment, especially in the case of acute or chronic cholecystitis mimicking a cancer of the gallbladder. By generalizing the practice of cytology of the bile of the gallbladder in research and in the improvement of a diagnosis as accurate as possible will lead to the deepening necessarily a better therapeutic management.

\section{Conflicts of Interest}

The authors declare no conflicts of interest regarding the publication of this paper. 


\section{References}

[1] Higuchi, R., Ota, T., Araida,T., Kajiyama, H., Yazawa, T., Furukawa, T., Yoshikawa, T., Takasaki, K. and Yamamoto, M. (2014) Surgical Approaches to Advanced Gallbladder Cancer. A 40-Year Single-Institution Study of Prognostic Factors and Resectability. Annals of Surgical Oncology, 21, 4308-4316. https://doi.org/10.1245/s10434-014-3885-1

[2] Ben-Josef, E., Guthrie, K.A., El-Khoueiry, A.B., Corless, C.L., Zalupski, M.M., Lowy, A.M., Thomas Jr., C.R, Alberts, S.R., Dawson, L.A., Micetich, K.C., Thomas, M.B., Siegel, A.B. and Blanke, C.D. (2014) SWOG S0809: A Phase II Intergroup Trial of Adjuvant Capecitabine and Gemcitabine Followed by Radiotherapy and Concurrent Capecitabine in Extrahepatic Cholangiocarcinoma and Gallbladder Carcinoma. Journal of Clinical Oncology, 33, 2617-2622. https://doi.org/10.1200/JCO.2014.60.2219

[3] Lendoire, J.C., Gil, L., Duek, F., Quarin, C., Garay, V., Raffin, G., Rivaldi, M., Alejandra, O. and Imventarza, O. (2012) Relevance of Residual Disease after Liver Resection for Incidental Gallbladder Cancer. $H P B, 14,548-553$. https://doi.org/10.1111/j.1477-2574.2012.00498.x

[4] Alonso de Ruiz, P., Albores-Saavedra, J., Henson, D.E. and Monroy, M.N. (1982) Cytopathology of Precursor Lesions of Invasive Carcinoma of the Gallbladder: A Study of Bile Aspirated from Surgically Excised Gallbladder. Acta Cytologica, 26, 144-152.

[5] Ishikawa, O., Ohhigashi, H., Sasaki, Y., Imaoka, S., Iwanaga, T., Wada, A., Ishiguro, S., Tateishi, R., Kishigami, Y. and Sone, H. (1988) The Usefulness of Saline-Irrigated Bile Intraoperative for the Cytologic Diagnosis of Tumors and Tumorlike Lesions of the Gallbladder. Acta Cytologica, 32, 475-481.

[6] Akosa, A.B., Barker, F., Desa, L., Benjamin, I. and Krausz, T. (1995) Cytologic Diagnosis in the Management of Gallbladder Carcinoma. Acta Cytologica, 39, 494-498.

[7] Hale, M.D., Roberts, K.J., Hodson, J., Scott, N., Sheridan, M. and Toogood, G.J. (2014) Xanthogranulomatous Cholecystitis: A European and Global Perspective. $H P B$, 16, 448-458. https://doi.org/10.1111/hpb.12152

[8] Gupta, P. and Gupta, R.K. (2012) Preoperative Diagnosis of Squamous Cell Carcinoma of the Gallbladder by Ultrasound-Guided Aspiration Cytology: Clinical and Cytological Findings of Nine Cases. Journal of Gastrointestinal Cancer, 43, 638-641. https://doi.org/10.1007/s12029-012-9413-2

[9] Jo, Y.G., Lee, T.H., Cho, H.D., Park, S.H., Park, J.M., Cho, Y.S., Jung, Y., Chung, I.K., Choi, H.J., Moon, J.H., Cha, S.W., Cho, Y.D. and Kim, S.J. (2014) Diagnostic Accuracy of Brush Cytology with Direct Smear and Cell-Block Techniques According to Preparation Order and Tumor Characteristics in Biliary Strictures. The Korean Journal of Gastroenterology, 63, 223-230. https://doi.org/10.4166/kjg.2014.63.4.223

[10] Vallilenga, C., Rodriguez Otero, J.C., Proske, S.A. and Celoria, G.C. (1995) Imprint Cytology of the Gallbladder Mucosa. Its Diagnosis in a Macroscopically Unapparent Carcinoma. Acta Cytologica, 39, 19-22.

[11] Arora, V.K., Kumar, S., Singh, N. and Bhatia, A. (2005) Intraoperative Cytology of the Bile Dysplasia-Carcinoma in Situ Sequence of Gallbladder Carcinoma. Cancer Cytopathology, 105, 277-281. https://doi.org/10.1002/cncr.21320

[12] Shukla, S., Krishnani, N., Jain, M., Pandey, R. and Gupta, R.K. (1997) Xanthogranulomatous Cholecystitis. Fine Needle Aspiration Cytology in 17 Cases. Acta Cytologica, 41, 413-418. https://doi.org/10.1159/000332533 
[13] Chang, B.J., Kim, S.H., Park, H.Y., Lim, S.W., Kim, J., Lee, K.H., Lee, K.T., Rhee, J.C., Lim, J.H. and Lee, J.K. (2010) Distinguishing Xanthogranulomatous Cholecystitis from the Wall-Thickening Type of Early-Stage Gallbladder Cancer. Gut and Liver, 4, 518-523. https://doi.org/10.5009/gnl.2010.4.4.518

[14] Sureka, B., Singh, V.P., Rajesh, S.R., Laroia, S., Bansal, K., Rastogi, A., Bihari, C., Bhadoria, A.S., Agrawal, N. and Arora, A. (2017) Computed Tomography (CT) and Magnetic Resonance (MR) Findings in Xanthogranulomatous Cholecystitis: Retrospective Analysis of Pathologically Proven 30 Cases-Tertiary Care Experience. Polish Journal of Radiology, 82, 327-332. 